Catherine M. Duffy MB BS,

Pirjo H. Manninen MD, Andrew Chan MB BS, Christopher F. Kearns MB BS

\section{Comparison of cerebral oximeter and evoked potential monitoring in carotid endarterectomy}

Purpose: To assess the cerebral oximeter, which measures regional oxygen saturation $\left(\mathrm{CSO}_{2}\right)$ continuously and noninvasively, as a cerebral monitor during carotid endarterectomy (CEA). The $\mathrm{rSO}_{2}$ was compared with Somatosensory Evoked Potentials (SSEPS) as an indicator for shunting and as a predictor of postoperative neurological deficits.

Methods: Seventy-two consenting patients undergoing CEA with general anaesthesia were studied. Normocarbia, normothermia and normotension were maintained. Cerebral monitoring consisted of bilateral median nerve SSEPS and the INVOS 3100 cerebral oximeter with the sensor pad placed on the ipsilateral forehead. Decreases in SSEP amplitude of $50 \%$ and in $\mathrm{rS}_{2}$ of $10 \%$ were considered clinically significant. Neurological assessment was performed at emergence from anaesthesia, $24 \mathrm{hr}$ postoperatively and at discharge. The $\mathrm{rSO}_{2}$ changes were compared with SSEP changes and with neurological deficits. Statistical analysis was with chi square and analysis of variance. $P<0.05$ was considered significant.

Results: During carotid artery clamping, $\mathrm{SO}_{2}$ decreased from $72 \pm 8 \%$ to $68 \pm 9 \%$ and mean arterial blood pressure increased from $92 \pm 14 \mathrm{mmHg}$ to $98 \pm 14 \mathrm{mmHg}$. In four patients, the carotid artery was shunted because of SSEP changes after cross-clamping. Five patients had $\geq 10 \%$ decreases in $\mathrm{rSO}_{2}$ following clamp application. Changes in both SSEP and $\mathrm{SO}_{2}$ occurred in two patients. Three of the four shunted patients had transient postoperative neurological deficits. One patient had a transient deficit without changes in either monitor. There were no persistent postoperative deficits. Compared with $\mathrm{SSEPS}, \mathrm{rSO}_{2}$ had a sensitivity of $50 \%$ and a specificity of $96 \%$.

Conclusion: Clinical experience with this evolving technology is ongoing. Its role in neurovascular procedures has yet to be established.

Objectif : Évaluer l'oxymètre cérébral, un appareil non invasif de mesure de la saturation régionale en oxygène $\left(\mathrm{rSO}_{2}\right)$ en continu, comme moniteur cérébral de l'endartérectomie carotidienne (EAC). L'étude compare la capacité de la rSO $\mathrm{S}_{2}$ de prédire le besoin de shunter et les déficits neurologiques postopératoires avec celle des potentiels évoqués somatosensoriels (PESS).

Méthodes : Soixante-douze patients consentants programmés pour une EAC sous anesthésie générale participaient à l'étude. L'expérience s'est déroulée dans des conditions de normocarbie, de normothermie et de normotension. Les PESS bilatéraux du nerf médian et l'oxymètre cérébral INVOS 3100 dont le capteur était placé à la région frontale homolatérale faisaient fonction de moniteurs cérébraux. Une baisse de l'amplitude de $50 \%$ des PESS et de $10 \%$ de la rSO2 était considérée d'importance clinique. Un examen neurologique était effectué au réveil, $24 \mathrm{~h}$ après l'intervention ainsi qu'au moment du congé. Les changements de la rSO $\mathrm{SO}_{2}$ ont été mis en parallele avec les changements des PESS et les déficits neurologiques. La comparaison statistique a utilisé la méthode du chi carré et l'analyse de variance, $P<0,05$ étant considéré comme significatif.

Résultats : Pendant le clampage de la carotide, la rSO $\mathrm{Sd}_{2}$ diminuait de $72 \pm 8 \%$ à $68 \pm 9 \%$ et la pression arténelle moyenne augmentait de $92 \pm 14 \mathrm{mmHg}$ à $98 \pm 14 \mathrm{mmHg}$. Quatre patients ont présenté une baisse de $210 \%$ de la sRO ${ }_{2}$ après l'application du clamp. Des changements de PESS et de $\mathrm{SO}_{2}$ concomitants sont survenus chez deux patients. Trois des quatre patients shuntés ont présenté des déficits neurologiques transitoires. Un patient a manifesté un déficit transitoire demeuré invisible sur les moniteurs. Aucun patient n'a souffert de déficit postopératoire permanent. Comparativement aux PESS, la rSO2 avait une sensibilité de $50 \%$ et une spécificité de $96 \%$.

Conclusion : L'expérimentation clinique de cette nouvelle technologie suit son cours. Son rôle reste à déterminer pour les interventions neurovasculaires.

From the Department of Anaesthesia, University of Toronto, The Toronto Hospital, Western Division, 399 Bathurst Strect, Toronto, Ontario M5T 2S8. This study was supported by Trudell Medical.

Address correspondence to: Dr. Pirjo H. Manninen.

Accepted for publication July $21,1997$. 


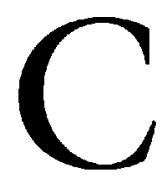

AROTID endarterectomy (CEA) has been demonstrated to be beneficial in patients with high grade carotid stenosis. ${ }^{1,2}$ However, this surgery is associated with a $2-7.5 \%$ risk of perioperative stroke which may be haemodynamic or embolic in origin. ${ }^{1-3}$ To minimize this risk, some centres choose to use intraoperative cerebral monitors to warn of impaired cerebral perfusion. A change in monitoring during carotid artery cross-clamping may be an indication for intervening with physiological manipulations, such as induced hypertension, or mechanical manoeuvres, such as insertion of a shunt. Cerebral monitoring of the patient's response may also act as a predictor of postoperative neurological status.

At our institution, median nerve somatosensory evoked potential (SSEP) monitoring is the standard cerebral function monitor during CEA. A $50 \%$ reduction in amplitude of $\mathrm{N} 20$ following application of the cross-clamp is used as the indicator for shunting. The Somanetics INVOS 3100 Cerebral Oximeter is a new cerebral monitor that uses near-infrared spectroscopy (NIRS) to measure regional cerebral oxygen saturation. It has the advantages of being continuous, noninvasive, portable, easy to use and is not affected by anaesthetic agents. The purpose of this study was to compare NIRS with SSEP monitoring during CEA as an indicator for shunting and as a predictor of postoperative neurological deficit.

\section{Methods}

With Ethics Committee approval, we studied 72 consenting patients undergoing CEA with general anaesthesia. Prior to induction of anaesthesia, an intravenous infusion of normal saline was commenced and a 20 gauge radial intraarterial line was inserted. Routine monitoring included: five lead electrocardiography, invasive and non-invasive blood pressure, pulse oximetry, end-tidal capnography and vapour analysis, peripheral nerve stimulation, oesophageal stethoscope and oesophageal temperature probe. The cerebral monitors were the Somanetics Invos 3100 Cerebral Oximeter and SSEPs.

Prior to induction, the self-adhesive probe of the cerebral oximeter was applied to the forehead ipsilateral to the site of surgery using tape to exclude ambient light. The screen displays trends using values recorded at 30- or $60-\mathrm{sec}$ intervals and absolute values of regional oxygen saturation $\left(\mathrm{rSO}_{2}\right)$ which change every four seconds. When an adequate tracing was obtained, a baseline $\mathrm{rSO}_{2}$ was recorded. Any changes, especially at the time of cross clamping, were noted by the investigator. On the basis of previous studies, ${ }^{4-6}$ a decrease in saturation of $210 \%$ was considered clini- cally significant. The surgeon was not informed of changes in cerebral oxygen saturation.

An electrophysiology technician was present throughout the surgery to perform monitoring of SSEPs as is the routine practice at our institution. Following induction of anaesthesia, stimulating needle electrodes were placed over both median nerves and recording needle electrodes were inserted in the scalp over the somatosensory cortex (C3' and C4') and over the $\mathrm{C} 2$ spine. The reference electrode was placed on the forehead. Bilateral baseline SSEPs were recorded using standard parameters. The SSEPs were monitored continuously during carotid cross clamping. Clinically significant SSEP changes were defined as a $>50 \%$ reduction in the amplitude of the cortical peak N20. The surgeon was informed of SSEP changes and a shunt inserted at his discretion.

Anaesthesia was induced with $2-3 \mu \mathrm{g} \cdot \mathrm{kg}^{-1}$ fentanyl, a sleep dose of propofol or thiopentone. An appropriate muscle relaxant was given to facilitate tracheal intubation. Anaesthesia was maintained with oxygennitrous oxide $\left(\mathrm{FiO}_{2} 0.5\right)$, isoflurane, boluses of fentanyl and non-depolarizing muscle relaxants. Normothermia was maintained. Arterial blood gases were analysed and mechanical ventilation controlled to keep $\mathrm{PaCO}_{2}$ between 38 and $42 \mathrm{mmHg}$. Blood pressure was maintained at preoperative levels using appropriate titration of anaesthetic agents, fluid administration and phenylephrine.

Neurological assessment was performed by the neurosurgeon immediately postoperatively, $24 \mathrm{hr}$ after surgery and on discharge from hospital. New neurological deficits were classified as transient if they lasted $<24 \mathrm{hr}$ and persistent if $>24 \mathrm{hr}$.

Statistical analysis was with chi square and analysis of variance. $P<0.05$ was considered significant. Changes in cerebral oximetry were compared with SSEP changes and with postoperative neurological deficits. The sensitivity and specificity of cerebral oximetry compared with SSEPs were calculated.

\section{Results}

Fifty-three male and 19 female patients with a mean $( \pm S D)$ age of $67( \pm 9) \mathrm{yr}$ and weight of $78 \pm 21 \mathrm{~kg}$ were studied. Duration of cross-clamp time was $51 \pm$ $22 \mathrm{~min}$. Core body temperature was $35.5 \pm 0.7^{\circ} \mathrm{C}$. During cross-clamping, there was an increase in mean arterial blood pressure (MAP). Heart rate and arterial oxygen saturation, as measured by pulse oximetry, remained stable. Cross-clamping was associated with a decrease in $\mathrm{rSO}_{2}$ which increased towards baseline values following release of the clamp. (Table I)

Four of the 72 patients had $>50 \%$ reduction in SSEP amplitude following cross-clamping. (Table II) 
TABLE I Measured variables (mean \pm SD)

\begin{tabular}{llll}
\hline & Preclamp & Clamp on & Clamp off \\
\hline $\mathrm{MAP}(\mathrm{mmHg})$ & $92 \pm 14$ & $98 \pm 14^{\star}$ & $90 \pm 13$ \\
$\mathrm{HR}(\mathrm{bpm})$ & $65 \pm 13$ & $66 \pm 13$ & $66 \pm 13$ \\
$\mathrm{SaO}_{2}(\%)$ & $98 \pm 1$ & $98 \pm 1$ & $98 \pm 1$ \\
$\mathrm{rSO}_{2}(\%)$ & $72 \pm 8$ & $68 \pm 9^{\star}$ & $70 \pm 8$ \\
\hline
\end{tabular}

${ }^{\star} P<0.05$ from preclamp \& clamp off

TABLE II Relationship of changes in $\mathrm{rSO}_{2}$ to changes in SSEP

\begin{tabular}{lll}
\hline & $\mathrm{rO}_{2}$ & $\mathrm{No}$ rSO \\
& 2 & 2 \\
SSEP Change \\
No SSEP Change & 3 & 65 \\
\hline
\end{tabular}

$\mathrm{rSO}_{2}$ change $=$ decrease $\geq 10 \%$

SSEP change $=$ decrease in amplitude $\mathrm{N} 2 \mathrm{O} \geq 50 \%$

In all cases, the SSEP returned to baseline after shunt insertion. In five patients, application of the clamp was associated with $210 \%$ decrease in $\mathrm{rSO}_{2}$ which lasted the duration of clamp time. Changes in $\mathrm{rSO}_{2}$ coincided with SSEP changes in two patients.

Three of the four shunted patients sustained transient postoperative neurological deficits. (Table III) Another patient had a transient deficit without changes in either SSEP or $\mathrm{rSO}_{2}$. In all four patients the deficit was contralateral weakness noted on emergence from anaesthesia and lasting less than six hours. There were no persistent postoperative neurological deficits. One patient in this series died within $24 \mathrm{hr}$ of surgery. This patient suffered a fatal intracerebral haemorrhage secondary to uncontrolled postoperative hypertension.

Relative to SSEPs, there were two true positive $\mathrm{rSO}_{2}$ changes, three false positives, two false negatives and 65 true negatives. (Table II) Compared with SSEP changes, a $10 \%$ reduction in $\mathrm{rSO}_{2}$ has a sensitivity of $50 \%$ and a specificity of $96 \%$.

\section{Discussion}

Central nervous system monitors fall into two main groups, those that monitor functional endpoints and those that monitor oxygen supply to the brain. The functional monitors which have been used in CEA are the awake patient, EEG and SSEPs. Stump pressure measurement, xenon measurements of cerebral blood flow, Doppler assessment of flow velocity, intraoperative angiography, jugular venous oxygen content and now NIRS monitor oxygen supply indirectly.

The application of NIRS to the noninvasive study of human cerebral metabolism was described by Jobsis in $1977 . .^{7}$ It is based on the Beer-Lambert law which states that the absorption of light is proportional to the concentration of chromophores, their absorption coefficients and the optical path length. Near infrared light, in the wavelength range of $650-1100 \mathrm{~nm}$, penetrates human scalp, skull and cranial contents for sevcral centimetres. It is absorbed by oxyhaemoglobin, deoxyhaemoglobin and oxidized cyctochrome $\mathrm{aa}_{3}$ at characteristic wavelengths $(900 \mathrm{~nm}, 760 \mathrm{~nm}$ and $780-870 \mathrm{~nm}$ respectively). The absorption of light by oxyhaemoglobin relative to total haemoglobin, with a small contribution by the redox state of cytochrome $\mathrm{aa}_{3}$ is used to deduce cerebral oxygen saturation. ${ }^{8}$

Intracranial attenuation of light is detected by two sensors. Attenuation due to superficial tissues, measured by the sensor closer to the light source, is subtracted from the total attenuation, measured by the more distant sensor, to derive attenuation of light due to intracranial contents. ${ }^{9}$ The cerebral oximeter used in our study has a source-detector distance of 30 and $40 \mathrm{~mm}$. Because previous source-detector distances of 10 and $27 \mathrm{~mm}$ enhanced interference from external circulation, ${ }^{10,11}$ distances were increased to 30 and 40 $\mathrm{mm}$ in newer models. However a recent study has shown application of a scalp tourniquet induced a decrease in $\mathrm{rSO}_{2}$, suggesting external circulation interference even at distances of 30 and $40 \mathrm{~mm} .{ }^{12}$ There may be inter-individual variation in the distribution of external and internal cerebral circulation. Change in $\mathrm{rSO}_{2}$ following application of the external carotid artery clamp in our study may have provided a measure of external circulation interference.

Since $70-80 \%$ of the cerebral cortical vascular bed is venous, the oxygen saturation that is measured is predominantly venous. Values are, therefore, affected by oxygen extraction, arterial oxygen content and blood flow. Because the proportion of venous blood volume remains constant under controlled physiolog-

TABLE III Relationship of changes in $\mathrm{rSO}_{2}$ and SSEP to postoperative neurological deficits

\begin{tabular}{lllll}
\hline & $S S E P$ & $r \mathrm{SO}_{2}$ & $r \mathrm{SO}_{2}$ \& SSEP change & No change \\
\hline Neurological Deficit & $1^{*}$ & - & $2^{*}$ & 1 \\
No Neurological Deficit & $1^{*}$ & 3 & - & 64 \\
\hline
\end{tabular}

* $=$ shunted

All postoperative neurological deficits were transient. 
ical conditions and cross clamping defines the onset of a potential cerebral insult, CEA lends itself to cerebral oximetry monitoring.

To date, regional cerebral oxygen saturation during CEA has been found to correlate with jugular venous oxygen saturation, ${ }^{10,13}$ transcranial Doppler measure of cerebral artery blood flow velocity ${ }^{10,13,14}$ and subjective assessment of internal carotid artery (ICA) backflow. ${ }^{6}$ In our study, we found that changes in $\mathrm{rSO}_{2}$ did not reliably relate to clinically important changes in SSEPs. This is the first published study examining the relationship between SSEPs and cerebral oximetry.

Since there is considerable inter-individual variation in baseline measures of $\mathrm{rSO}_{2},{ }^{4,6,13,17}$ it is appropriate to use relative changes in $\mathrm{rSO}_{2}$, rather than absolute values. Clinical experience with this technology is evolving. At this stage, a change in $\mathrm{rSO}_{2}$ of $10 \%$ appears to be a reasonable arbitrary threshold. $4,5,6$

In our study, blood pressure increased following application of the cross-clamp. This reflects the practice of maintaining or increasing blood pressure during cross-clamping. In previous studies, $\mathrm{rSO}_{2}$ has been sensitive to blood pressure changes. ${ }^{15,16}$ It is possible that a more marked decrease in $\mathrm{rSO}_{2}$ during carotid clamping could be expected if hypertension had not been maintained.

Disparity between cerebral oximetry and SSEPs may be attributable to their monitoring of different regions of cerebral circulation. Placement of the oximeter selfadhesive probe on the forehead detects changes in circulation to the frontal lobe whereas SSEPs detect changes in the distribution of the middle cerebral artery. Unfortunately, placement of the probe over the parietal lobe would require shaving the patient's head. Williams et $a l .{ }^{10}$ found improved correlation between $\mathrm{rSO}_{2}$ and jugular venous oxygen saturation when the probe was placed over the parietal lobe and sourcedetector distance was increased. From their study, it is difficult to determine how much of the improvement was due to a change in probe placement and how much to a change in source-detector distance.

Evaluation of a cerebral monitor for CEA surgery is problematic. The prevalence of postoperative neurological deficit is so $l w^{1-3}$ that a very large number of patients would need to be studied to calculate negative and positive predictive values of a new monitor. Sensitivity and specificity require comparison with an accepted standard. At our institution, the standard for monitoring during CEA is SSEPs. Compared with SSEPs, we found a change in $\mathrm{rSO}_{2}$ of $210 \%$ had a low sensitivity and high specificity. The ideal monitor for detection of impending cerebral ischaemia during CEA should have high sensitivity.
Another standard for CEA monitoring is an awake patient. The few studies of cerebral oximetry in the awake patient have found that changes in $\mathrm{rSO}_{2}$ were not associated with changes in the patient's neurological condition. ${ }^{17,18}$ Like us, both studies of awake patients report a decrease in $\mathrm{rSO}_{2}$ during carotid artery clamping. In the study by Samra $e t a l .,{ }^{17}$ patients were monitored bilaterally to differentiate systemic causes of changes in $\mathrm{rSO}_{2}$, such as hypoxaemia and hypotension, from causes related to surgery. This improves the yield of information and may be a useful application of the monitor.

Comparison of the cerebral oximeter with established cerebral monitors has produced varying results. While it has the advantages of being non-invasive and easy to use, its limitations are that it is a regional, superficial monitor of cerebral oxygenation. As such, the probe should be placed over the area of circulation at risk. The issue of external circulation remains unresolved, even with increased source-detector distances. Further refinement of the technology is ongoing. With more clinical experience, the ultimate role of the cerebral oximeter in neurovascular procedures will be established.

\section{Acknowledgement}

The authors wish to acknowledge Dr. Shanthini Sundareswaran for her help with collection of data for this study.

\section{References}

1 North American Symptomatic Carotid Endarterectomy Trial Collaborators. Beneficial effect of carotid endarterectomy in symptomatic patients with highgrade carotid stenosis. N Eng J Med 1991; 325: 445-53.

2 European Carotid Surgery Trialists' Collaborative Group. MRC European Carotid Surgery Trial: interim results for symptomatic patients with severe (70-99\%) or with mild (0-29\%) carotid stenosis. Lancet 1991; 337: 1235-43.

3 Sundt TM Jr, Whisnant JP, Houser OW, Fode NC. Prospective study of the effectiveness and durability of carotid endarterectomy. Mayo Clin Proc 1990; 65: 625-35.

4 Hernandez-Avila G, Dujovny $M$, Slapin $K V$, et al. Use of transcranial cerebral oximetry to monitor regional cerebral oxygen saturation during neuroendovascular procedures. Am J Neuroradiol 1995; 16: 1618-25.

5 Dujovny M, Slavin KV, Hernandez G, Geremia GK, Ausman $J I$. Use of cerebral oximetry to monitor brain oxygenation reserves for skull base surgery. Skull Base Surgery 1994; 4: 117-21. 
6 Duncan LA, Ruckley CV, Wildsmith JAW. Cerebral oximetry: a useful monitor during carotid artery surgery. Anaesthesia 1995: 50; 1041-5.

7 McCormick PW, Stewart $M$, Goetting $M G$, Dujovny $M$, Lewis G, Ausman JI. Noninvasive cerebral optical spectroscopy for monitoring cerebral oxygen delivery and hemodynamics. Crit Care Med 1991; 19: 89-97.

8 Slavin KV, Dujovny M, Ausman JI, Hernandez G, Luer $M$, Stoddart $H$. Clinical experience with transcranial cerebral oximetry. Surg Neurol 1994: 42: 531-40.

9 Jobsis FF. Noninvasive infrared monitoring of cerebral and myocardial oxygen sufficiency and circulatory parameters. Science 1977; 198: 1264-7.

10 Williams IM, Picton A, Farrell A, Mead GE, Mortimer AJ, McCollum CN. Light-reflective cerebral oximetry and jugular bulb venous oxygen saturation during carotid endarterectomy. Br J Surg 1994; 81: 1291-5.

11 Harris DNF, Bailey SM. Near infrared spectroscopy in adults. Does the Invos 3100 really measure intracerebral oxygenation? Anaesthesia 1993; 48: 694-6.

12 Germon TJ, Kane NM, Manara AR, Nelson RJ. Nearinfrared spectroscopy in adults: effects of extracranial ischaemia and intracranial hypoxia on estimation of cerebral oxygenation. Br J Anaesth 1994; 73: 503-6.

13 Williams IM, Mead G, Picton AJ, Farrell A, Mortimer $A J, M c$ Collum $C N$. The influence of contralateral carotid stenosis and occlusion on cerebral oxygen saturation during carotid artery surgery. Eur J Vasc Endovasc Surg 1995; 10: 198-206.

14 Doblar DD, Lim YC, McDowell $H$. Temporal relationship between transcranial Doppler velocity and near infrared cerebral spectroscopy during carotid endarterectomy. Anesthesiology 1994; 81: A195.

15 Smith DS, Levy $W$, Maris $M$, Chance B. Reperfusion hyperoxia in brain after circulatory arrest in humans. Anesthesiology 1990; 73: 12-9.

16 Williams IM, Picton AJ, Hardy SC, Mortimer AJ, $M c$ Collum $C N$. Cerebral hypoxia detected by near infrared spectroscopy. Anaesthesia 1994; 49: 762-6.

17 Samra SK, Dorje P, Zelenock GB, Stanley JC.Cerebral oximetry in patients undergoing carotid endarterectomy under regional anesthesia. Stroke 1996; 27: 49-55.

18 Mascia MF, McGraw DJ, Camporesi EM. The use of near infrared cerebral oximetry in awake carotid endarterectomy. Anesthesiology 1994; 81: A532. 